論文

\title{
ポリシルセスキオキサンゲート絶縁膜の表面平坦化によるペンタセン 薄膜トランジスタのキャリア移動度の向上†
}

道浦 大祐* 中原 佳夫* 宇野 和行** 田中 一郎**

\section{Improving the Carrier Mobility of Pentacene Thin Film Transistors by Surface Flattened Polysilsesquioxane Gate Dielectric Layers}

by

\author{
Daisuke Michiura*, Yoshio NAKaharA*, Kazuyuki Uno** and Ichiro TANAKA**
}

The surface flatness of photo-curable polysilsesquioxane (PSQ) films for gate dielectric layers of pentacene thin film transistors (TFTs) was considerably improved by ultra-violet light (UV) $/ \mathrm{O}_{3}$ treatment; the root-mean-squared (RMS) roughness was improved from 0.35 to $0.23 \mathrm{~nm}$ after 40 -minute treatment. However, the PSQ surfaces became hydrophilic because hydroxyl groups, which degraded transistor performances, replaced the organic functional groups such as methyl groups by the $\mathrm{UV} / \mathrm{O}_{3}$ treatment. Therefore, 1,1,1,3,3,3-hexamethyldisilazane (HMDS) treatment was successively performed after the $\mathrm{UV} / \mathrm{O}_{3}$ treatment to replace the hydroxyl groups with hydrophobic silyl groups. It was found that four-hour HMDS treatment under dry nitrogen was enough to reduce off current of pentacene TFTs. As a result, the carrier mobility of the pentacene TFT fabricated with $\mathrm{UV} / \mathrm{O}_{3}$ and $\mathrm{HMDS}$-treated PSQ layers became 0.59 $\mathrm{cm}^{2} \mathrm{~V}^{-1} \mathrm{~s}^{-1}$, which was more than seven times higher than that of the pentacene TFTs with untreated PSQ layers.

\section{Key words:}

Polysilsesquioxane, Gate dielectric layers, Surface flatness, Pentacene, Thin film transistors, $\mathrm{UV} / \mathrm{O}_{3}$, 1,1,1,3,3,3-hexamethyldisilazane

\section{1 緒言}

有機エレクトロニクスは，有機材料の機械的柔軟性, 軽量性や溶媒に可溶という性質から，低コストで大面積 かつフレキシブルなデバイスが実現できるため注目され ている，そのため，有機エレクトロルミネッセンス素子 や有機太陽電池などのいろいろな有機デバイスについて の研究が近年盛んに行われている. 有機薄膜トランジス 夕(OTFT)もその一つである. OTFT は有機材料が持つ特徵 を活かして，電子ペーパーや RFID タグ，バイオセンサー への応用が期待されている。1 ${ }^{1) 3}$

低コストでフレキシブルな OTFT の実現には，その基 板に汎用プラスチックを用いる必要がある。しかし，汎

(a)

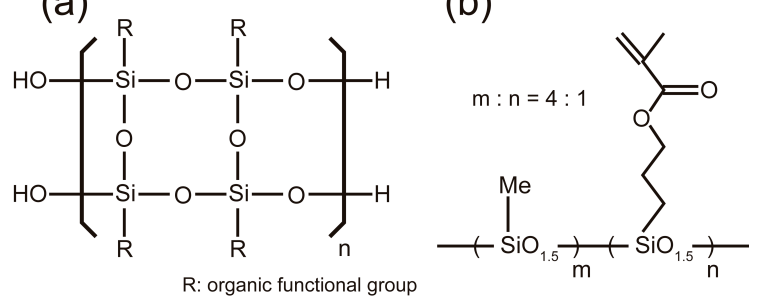

Fig. 1 The molecular structures of (a) PSQ and (b) the PSQ used in this study, which is modified with 3-methacryloxypropyl groups.
用プラスチックは熱に弱い，例えば，ポリエチレンテレ フタラートのガラス転移温度は約 $80{ }^{\circ} \mathrm{C}$ である。 ${ }^{4)}$ その ため, OTFT を構成する材料は基板のガラス転移温度より も低い温度で成膜できるものが必要である.

OTFT のポリマーゲート絶縁膜材料として,これまでに ポリイミドやポリビニルフェノールが報告されている. しかし，これらの重合温度は約 $200{ }^{\circ} \mathrm{C}$ であり，汎用プラ スチック基板上への成膜は難しい。 ${ }^{5), 6)}$ そのため，より 低温で重合できる新規のゲート絶縁膜材料が必要とされ ている。その候補として，われわれはポリシルセスキオ キサン(PSQ)を検討している. ${ }^{7)}$ Fig. 1(a)にPSQ の構造 を示す. PSQ はシロキサン結合から成る主鎖に側鎖の有 機官能基が結合している構造を有する。このため，有機 官能基の種類を用途に合わせて選択することで，新たな 特徵を付け加えることができる。例えば，Fig. 1(b)のよう

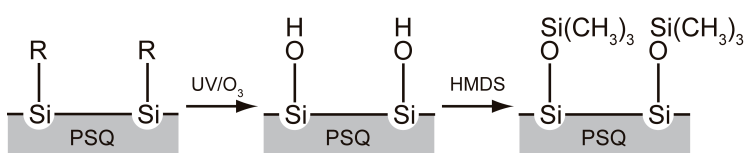

Fig. 2 The model for $\mathrm{UV} / \mathrm{O}_{3}$ and HMDS treatment of the PSQ surfaces.

$\dagger$ 原稿受理 平成29年 2月10日 Received Feb. 10, 2017 @2017 The Society of Materials Science, Japan

* 和歌山大学 システム工学部 † 640-8510 和歌山市栄谷

Faculty of Systems Engineering, Wakayama University, Sakaedani, Wakayama 640-8510.

** 正会員 和歌山大学 システム工学部 ₹640-8510 和歌山市栄谷

Faculty of Systems Engineering, Wakayama University, Sakaedani, Wakayama 640-8510. 
に光重合性の 3-メタクリロキシプロピル基を側鎖に付与 すれば，紫外線(UV)照射によって重合する PSQ を合成す ることができる。この PSQ は $120^{\circ} \mathrm{C}$ 程度の加熱によるゾ ルゲル重合も可能であるが 7), UV 重合させればそれより も低い温度でゲート絶縁膜を作製できる。そこでわれわ れは，3-メタクリロキシプロピル基を側鎖に有する PSQ をUV 重合させたゲート絶縁膜を用いて有機 TFT を作製 し，その評価を行ってきた. ${ }^{8), 9)}$

OTFT のゲート絶縁膜について研究する上で, その表面 の性質を知ることは非常に重要である. 特に, ゲート絶 縁膜表面の凹凸はチャネルを流れるキャリアの散乱要因 になるほか，真空蒸着法などで有機半導体薄膜を形成す る際にその分子のマイグレーションを阻害するため多結 晶有機半導体膜を構成するグレインが小さくなる，すな わちグレイン境界密度が増大寸ることが知られている. ${ }^{10)}$ そのため, ゲート絶縁膜表面の平坦化は, OTFT のキャリ ア移動度向上に大きく貢献する。 また，ゲート絶縁膜上 のヒドロキシ基はキャリアを散乱するほか，才フ電流を 増加させる. ${ }^{11)}$ そのため, シランカップリング剤による ヒドロキシ基の除去が一般的に行われている。 ${ }^{12)}$ Fig. 1(b)に示した PSQ をスピンコートし、UV 重合させたゲー 卜絶縁膜の表面凹凸の自乗平均平方根(RMS)は $0.4 \mathrm{~nm}$ 程 度であり, 研究室レベルでよく使用される熱酸化 $\mathrm{SiO}_{2}$ ゲ 一ト絶縁膜の表面凹凸の RMS が $0.15 \mathrm{~nm}$ 程度であるのに 比べると平坦性が悪い，そこで，われわれは，PSQ 絶縁 膜の表面に $\mathrm{UV} / \mathrm{O}_{3}$ 処理とへキサメチルジシラザン (HMDS)処理を施すことで, ペンタセン TFT のキャリア移 動度を改善できることをすでに報告した。13)

その報告では, PSQ 絶縁膜表面の凹凸の RMS は $0.31 \mathrm{~nm}$ に改善され，ペンタセン TFT のキャリア移動度は未処理 のPSQ 絶縁膜を用いた場合の $0.082 \mathrm{~cm}^{2} \mathrm{~V}^{-1} \mathrm{~s}^{-1}$ から約 4 倍 に向上し， $0.31 \mathrm{~cm}^{2} \mathrm{~V}^{-1} \mathrm{~s}^{-1}$ になったが，PSQ 絶縁膜の表面 処理条件は，まだ最適化されたものではなかった。

そこで今回は, それぞれの表面処理についてより詳細に 検討し，ペンタセン TFT のキャリア移動度をさらに向上 させることを目的とした。

\section{2 実験方法}

$\mathrm{UV} / \mathrm{O}_{3}$ 処理は PSQ 絶縁膜表面を平坦化し, HMDS 処理 は Fig. 2 に示すように $\mathrm{UV} / \mathrm{O}_{3}$ 処理によってできた PSQ 絶 縁膜表面のヒドロキシ基をシリル基に置換して除去する 効果がある. 前回の報告では, 20 分間の $\mathrm{UV} / \mathrm{O}_{3}$ 処理と 16 時間の HMDS 処理を大気中で行った PSQ 絶縁膜を用いて ペンタセン TFT を作製した。今回は, $\mathrm{UV} / \mathrm{O}_{3}$ 処理につい てはその処理時間の最適化を行い，これまでより表面平 坦性の高い PSQ 絶縁膜を得る検討を行った. また, HMDS 処理については，水分の影響を減らすために乾燥窒素雾 囲気下で処理を行うように変更し，さらにその処理時間 の短縮について検討した。
本研究ではボトムゲートトップコンタクト型のペンタ セン TFT を作製した，その作製方法は以下のとおりであ る.まず，低分子架橋剤であるトリメチロールプロパン トリアクリレートと溶媒のプロピレングリコールモノメ チルエーテルアセテートを体積比 1:4 の割合で混合し, そ こに重合開始剤として $2 \mathrm{wt} \%$ の 1-ヒドロキシシクロヘキ シルフェニルケトンを加えた．そこに，PSQ $\left(M_{\mathrm{w}}=\sim 3000\right)$ を加え， $33 \mathrm{wt} \%$ の PSQ 溶液を調整した。この PSQ 溶液を アセトンで超音波洗浄した $\mathrm{n}^{+}-\mathrm{Si}(001)$ 基板上に滴下し，30 秒間 $7000 \mathrm{rpm}$ でスピンコートした. その後, 高圧水銀ラ ンプを用い窒素雰用気中でピーク波長 $365 \mathrm{~nm}$ の UV 光を 60 分間照射して PSQ を重合させた。 このとき, UV 光の 強度は $120 \mathrm{~mW} / \mathrm{cm}^{2}$ であった。この方法で作製した PSQ 絶縁膜の厚さは 1.0 $\mu \mathrm{m}$ であり，また，抵抗率は $10^{14} \Omega \mathrm{cm}$ であった。

重合した PSQ 絶縁膜の $U V / \mathrm{O}_{3}$ 処理は, 大気中で波長 185 $\mathrm{nm}$ および $254 \mathrm{~nm}$ のUV光を照射することにより行った. また，HMDS 処理は乾燥窒素に置換したグローブボック ス内でPSQ 絶縁膜を HMDS 蒸気雾囲気中に置くことによ り行った.

ペンタセン薄膜は真空蒸着法によって PSQ 絶縁膜の上 に形成した. 蒸着時の真空度は $10^{-5} \mathrm{~Pa}$ で, $0.01 \mathrm{~nm} / \mathrm{s}$ の蒸 着レートで厚さ $30 \mathrm{~nm}$ 堆積した。 さらに, メタルマスク を介して，このペンタセン薄膜上にソース・ドレイン電 極として厚さ $50 \mathrm{~nm}$ の金薄膜を蒸着した。作製したペン タセン TFT のチャネル長は 12 58 $\mu \mathrm{m}$ であり, チャネル幅 は $2 \mathrm{~mm}$ であった. 今回の実験ではトランジスタ特性の違 いを検討するために，未処理の PSQ 絶縁膜を使用したぺ ンタセン TFT を 12 個, 40 分間の $\mathrm{UV} / \mathrm{O}_{3}$ 処理に加えて 1 時間または 4 時間の HMDS 処理を行った PSQ 絶縁膜を用 いたペンタセン TFT をそれぞれ 6 個ずつ作製した。

ペンタセン薄膜のグレイン構造は原子間力顕微鏡 (AFM)を用いて観察した。また，HMDS 処理によるヒド ロキシ基のシリル基への置換を確認するために, PSQ 絶 縁膜のフーリエ変換赤外分光測定(FT-IR)を行い，シリル 基に含まれる $\mathrm{Si}-\mathrm{C}$ 結合による吸収ピーク強度を測定した。 ペンタセン TFT のトランジスタ特性測定は半導体パラメ ータアナライザ 4145B を用いて行った。このとき, 試料 を 1 $\mathrm{Pa}$ の真空下に置き，かつ遮光した状態で測定した. また, キャリア移動度 $\mu$ としきい值電圧 $V_{t h}$ は(1)式から算 出した。

$$
I_{D S}=(W / 2 L) \mu C_{i}\left(V_{G}-V_{t h}\right)^{2}
$$

ここで $L$ と $W$ はそれぞれチャネル長とチャネル幅であ り， $I_{D S}$ と $V_{G}$ はそれぞれ飽和領域でのドレイン電流とゲー 卜電圧を表す。また， $C_{i}$ はゲート絶縁膜の単位面積あた りの静電容量である。PSQ 絶縁膜の静電容量の測定は LCR メタ 4284A を用いて行った。

\section{3 結果と考察}

\section{$3 \cdot 1$ 表面処理条件の検討}



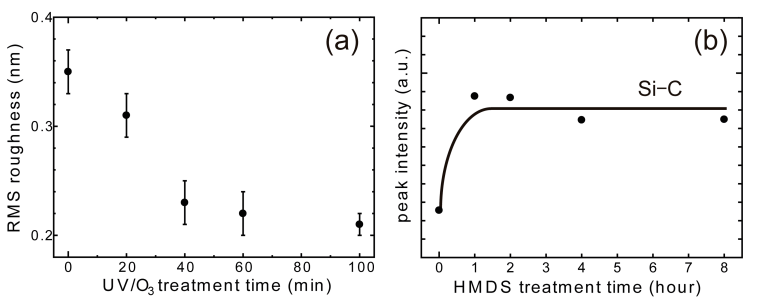

Fig. 3 (a) Surface roughness as a function of $\mathrm{UV} / \mathrm{O}_{3}$ treatment time. (b) IR absorption peak intensity of Si-C bonds as a function of HMDS treatment time.
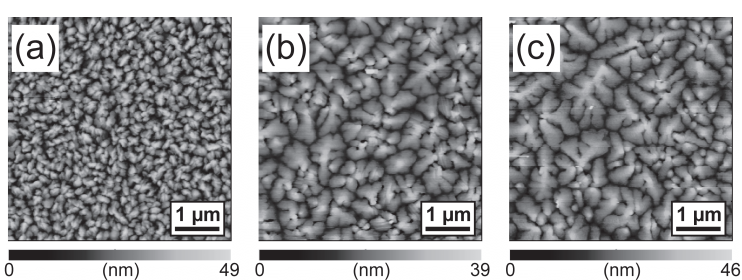

Fig. 4 AFM images of the pentacene layers deposited on (a) the untreated PSQ layers, on the PSQ layers treated with $\mathrm{UV} / \mathrm{O}_{3}$ for 40 min and with HMDS for (b) $1 \mathrm{~h}$, and (c) $4 \mathrm{~h}$.

PSQ 絶縁膜の表面凹凸の RMS と UV/O 3 処理の処理時 間の関係を Fig. 3(a)に示す. UV/O 3 処理時間が長くなる につれて $\mathrm{PSQ}$ 絶縁膜表面が平坦になり, 40 分間の $\mathrm{UV} / \mathrm{O}_{3}$ 処理で RMS は $0.35 \pm 0.02 \mathrm{~nm}$ から $0.23 \pm 0.02 \mathrm{~nm}$ まで改 善した。しかし，処理時間が 40 分以上になるとそれ以 上はあまり平坦化されなくなった。したがって, $\mathrm{UV} / \mathrm{O}_{3}$ 処理時間は 40 分間が適切と考えられる。 また, PSQ 絶 縁膜の $\mathrm{UV} / \mathrm{O}_{3}$ 処理をドライ酸素中で 40 分間行った場合 の表面凹凸の RMS は約 $0.30 \mathrm{~nm}$ であり, 大気中で処理 した場合よりも平坦化の効果が小さかった。この結果か ら, 大気中の水分が平坦化に影響していると推測できる われわれは, $\mathrm{UV} / \mathrm{O}_{3}$ 処理によって PSQ 絶縁膜表面が平坦 化される理由は, 主に大気中に含まれている水分によっ て膜表面の PSQ の主鎖のシロキサン結合が加水分解さ れるためだと考えている。 ${ }^{14)}$

次に, HMDS 処理の最適処理時間を調べるために, 乾 燥窒素雾囲気下で HMDS 処理をした PSQ 絶縁膜の FT-IR スペクトルを測定した。 なお，このとき $\mathrm{UV} / \mathrm{O}_{3}$ 処理を 40 分間行った PSQ 絶縁膜を用いた. Fig. 3(b)は, 波数 1270 $\mathrm{cm}^{-1}$ におけるシリル基の $\mathrm{Si}-\mathrm{C}$ 結合由来の IR 吸収ピーク の大きさと, HMDS 処理時間の関係を示す. HMDS 処理 時間が長くなると, Si-C 結合由来の吸収ピークが増加す ることが分かる。この理由は，ヒドロキシ基が HMDS の シリル基に置換され，PSQ 絶緣膜表面に存在する Si-C 結 合の数が増加したためだと考えられる.ささらに，このピ ークの大きさは処理時間が 1 時間以上ではあまり変化し ないことから, HMDS 処理は 1 時間程度で飽和している と考えられる.
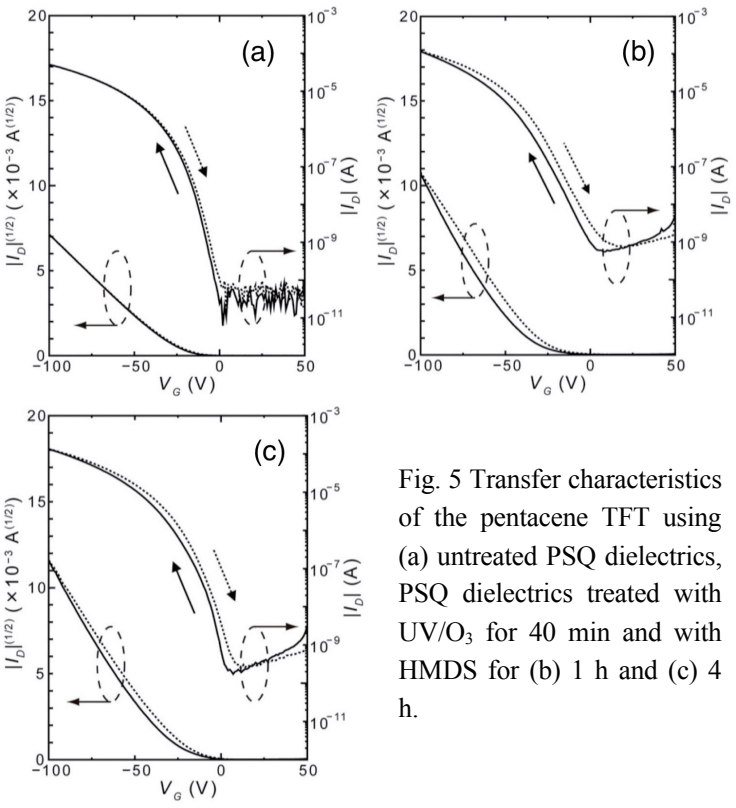

Fig. 5 Transfer characteristics of the pentacene TFT using (a) untreated PSQ dielectrics, PSQ dielectrics treated with $\mathrm{UV} / \mathrm{O}_{3}$ for $40 \mathrm{~min}$ and with HMDS for (b) $1 \mathrm{~h}$ and (c) 4 h.

\begin{tabular}{|c|c|c|c|}
\hline $\begin{array}{l}\text { Surface treatment of PSQ } \\
\text { dielectric layers }\end{array}$ & $\begin{array}{l}\text { Hole mobility } \\
\left(\mathrm{cm}^{2} \mathrm{~V}^{-1} \mathrm{~s}^{-1}\right)\end{array}$ & $\begin{array}{l}\text { Threshold } \\
\text { voltage } \\
\text { (V) }\end{array}$ & On/off ratio \\
\hline untreated & $0.082 \pm 0.026$ & $-29.6 \pm 5.4$ & $10^{4} \sim 10^{5}$ \\
\hline $\begin{array}{l}\text { 40-min } \mathrm{UV} / \mathrm{O}_{3} \& \\
\text { 1-h HMDS treatments }\end{array}$ & $0.59 \pm 0.11$ & $-42.8 \pm 5.6$ & $10^{4} \sim 10^{5}$ \\
\hline $\begin{array}{l}\text { 40-min } \mathrm{UV} / \mathrm{O}_{3} \& \\
\text { 4-h HMDS treatments }\end{array}$ & $0.59 \pm 0.14$ & $-39.3 \pm 3.2$ & $10^{5}$ \\
\hline
\end{tabular}

$3 \cdot 2$ ペンタセン薄膜のグレインサイズとペンタセン TFT のトランジスタ特性

Fig. 4(a)は未処理の PSQ 絶縁膜上に，Fig. 4(b) と4(c)は それぞれ 40 分の $\mathrm{UV} / \mathrm{O}_{3}$ 処理に加えて 1 時間または 4 時間 の HMDS 処理をしたPSQ 絶縁膜上に蒸着したペンタセン 薄膜表面の AFM 像である. 未処理の PSQ 絶縁膜の上に 蒸着した場合, グレインの大きさは数 $100 \mathrm{~nm}$ 程度しかな い. しかし, UV/O $/$ 処理の後, HMDS 処理を 1 時間また は 4 時間行った場合は大きさが $1 \mu \mathrm{m}$ 前後の樹枝状のグレ インが成長した。これは, UV/O 3 処理によって $\mathrm{PSQ}$ 絶縁 膜の表面凹凸の RMS が $0.35 \mathrm{~nm}$ から $0.23 \mathrm{~nm}$ に減少し, その平坦性が高くなったためであると考えられる.

Fig. 5(a) に未処理の PSQ 絶縁膜を用いたペンタセン TFT のトランスファー特性の例を示す． Fig. 5(b)と 5(c) は, 40 分間の $\mathrm{UV} / \mathrm{O}_{3}$ 処理に加えてそれぞれ 1 時間または 4 時間の HMDS 処理を行った PSQ 絶縁膜を用いたペンタ セン TFT のトランスファー特性の例である。 また, トラ ンスファー特性から求めたキャリア移動度としきい值電 圧の平均值, 並びにおおよそのオンオフ比を Table 1 に示 す. HMDS 処理を 1 時間行った場合と 4 時間行った場合 のキャリア移動度は同程度であり, その平均は共に 0.59 $\mathrm{cm}^{2} \mathrm{~V}^{-1} \mathrm{~s}^{-1}$ である。これは, 未処理の PSQ 絶緑膜を用いた 場合よりも 7 倍以上高い值であり, HMDS 処理した熱酸 化 $\mathrm{SiO}_{2}$ 絶縁膜を用いた場合と同程度である。このように キャリア移動度が向上した理由は, PSQ 絶緑膜の平坦性 
向上によりペンタセンのグレインが大きくなったことに 加えて絶縁膜の凹凸によるキャリア散乱が減少したこと が考えられる.

また, HMDS 処理を 4 時間行った場合は, 処理時間が 1 時間の場合に比べて，才フ電流が平均で $40 \%$ 程度に減少 してオンオフ比も向上し，ヒステリシスも小さくなった. これは 1 時間の HMDS 処理ではヒドロキシ基の除去が十 分ではなく，その影響が残っていたためであると考えら れる. FT-IR スペクトルの測定では 1 時間程度で Si-C 結 合による吸収ピーク強度が飽和したが，その後も FT-IR 測定に反映されない程度の反応が進んだと考えられる. なお, HMDS 処理をこれ以上行ってもさらなるオフ電流 の減少はみられなかったので，HMDS 処理は 4 時間以内 に飽和していると考えられる。

しかし，表面処理を行った PSQ 絶縁膜を用いた TFT の 方がしきい值電圧が $10 \mathrm{~V}$ 程度大きくなっており, まだヒ ステリシスも残っていることと併せて今後の検討が必要 である。

\section{4 結言}

われわれは PSQ 絶縁膜に 20 分間の $\mathrm{UV} / \mathrm{O}_{3}$ 処理と 16 時 間の HMDS 処理を行うことで, 未処理の PSQ 絶縁膜を使 用した場合に比べてペンタセン TFT のキャリア移動度を 約 4 倍に改善できることを以前に報告した. ${ }^{13)}$ そこで今 回は，それらの表面処理時間を最適化する検討を行った。 まず, $\mathrm{UV} / \mathrm{O}_{3}$ 処理時間と PSQ 絶縁膜表面凹凸の RMS の関 係を調べた。その結果，処理時間が 40 分間までは平坦性 が向上し，RMS が $0.23 \mathrm{~nm}$ に低下したが，それ以上処理 時間を長くしても平坦化はあまり進まなかった。今回， 40 分間の $\mathrm{UV} / \mathrm{O}_{3}$ 処理によって $\mathrm{PSQ}$ 絶縁膜の平坦性がさら に向上した結果, ペンタセン TFTのキャリア移動度は 0.59 $\mathrm{cm}^{2} \mathrm{~V}^{-1} \mathrm{~s}^{-1}$ に向上した。これは表面処理をしていない PSQ 絶縁膜を用いた場合の 7 倍以上である.

次に, 乾燥窒素雰囲気下での HMDS 処理時間とシリル 基の IR 吸収ピークの大きさの関係を調べた。その結果か らは, HMDS 処理は 1 時間程度で飽和していると考えら れる.しかし，実際にペンタセン TFT を作製したところ， HMDS 処理を 1 時間以上行うとさらにオフ電流が低減さ れ, 4 時間以内に飽和することが分かった。したがって， HMDS 処理時間は 4 時閒以下に短縮できると考えられる.

このように, PSQ 絶縁膜の平坦性向上によりキャリア 移動度が大幅に改善されたことに加えて, オフ電流值の 比較から HMDS 処理の時間も大きく短縮できることが分 かり，以前より効果的かつ効率的に PSQ 絶縁膜の表面処 理を行うことができるようになった.

\section{参 考 文 献}

1) C. D. Dimitrakopoulo and P. R. L. Malenfant, "Organic thin film transistors", Advanced Materials, Vol. 14, No. 2, pp. 99-117 (2002).
2) J. Zaumseil and H. Sirringhaus, "Electron and ambiolar transport in organic field-effect transistors", Chemical Reviews, Vol. 107, No. 4, pp. 1296-1323 (2007).

3) P. F. Moonen, I. Yakimets and J. Huskens, "Fabrication of transistors on flexible substrates: from mass-printing to high-resolution alternative lithography strategies", Advanced Materials, Vol. 24, No. 2, pp. 5526-5541 (2012).

4) H. Ohi, "Purasuchikku katsuyou noto", Chap. 2 (2006) Kogyo Chosakai Publishing Co., Ltd.

5) Y. Kato, S. Iba, R. Teramoto, T. Sekitani, T. Someya, H. Kawaguchi and T. Sakurai, "High mobility of pentacene field-effect transistors with polyimide gate dielectric layers", Applied Physics Letters, Vol. 84, Issue 19, pp. 3789-3791 (2004).

6) H. Klauk, M. Halik, U. Zschieschang, G. Schmid, W. Radlik and W. Weber, "High-mobility polymer gate dielectric pentacene thin film transistors", Journal of Applied Physics, Vol. 92, Issue 9, pp. 5259-5263 (2002).

7) M. Kawamura, Y. Nakahara, M. Ohse, M. Kumei, K. Uno, H. Sakamoto, K. Kimura, and I. Tanaka, "Investigation of polysilsesquioxane as a gate dielectric material for organic field-effect transistors", Applied Physics Letters, Vol. 101, Issue 5, pp. 053311-(1-4) (2012).

8) H. Shibao, Y. Nakahara, K. Uno, and I. Tanaka, "Investigation of ultraviolet light curable polysilsesquioxane gate dielectric layers for pentacene thin film transistors", Journal of Nanoscience and Nanotechnology, Vol. 16, No. 4, pp. 3327-3331 (2016).

9) Y. Matsuda, Y. Nakahara, D. Michiura, K. Uno, and I. Tanaka, "High-mobility 6,13-Bis(triisopropylsilylethynyl) pentacene transistors using solution-processed polysilsesquioxane gate dielectric layers", Journal of Nanoscience and Nanotechnology, Vol. 16, No. 4, pp. 3273-3276 (2016)

10) S. Steudel, S. D. Vusser, S. D. Jonge, D. Janssen, S. Verlaak, J. Genoe and P. Heremans, "Influence of the dielectric roughness on the performance of pentacene transistors", Applied Physics Letters, Vol. 85, Issue 19, pp. 4400-4402 (2004).

11) S. Lee, B. Koo, J. Shin, E. Lee, H. Park and H. Kim, "Effects of hydroxyl groups in polymeric dielectrics on organic transistor performance", Applied Physics Letters, Vol. 88, Issue 16, pp. 162109-(1-3) (2006).

12) A. Salleo, M. L. Chabinyc, M. S. Yang and R. A. Street, "Polymer thin-film transistors with chemically modified dielectric interfaces", Applied Physics Letters, Vol. 81, Issue 23, pp. 4383-4385 (2002).

13) D. Michiura, Y. Nakahara, K. Uno and I. Tanaka, "Improving the carrier mobility of pentacene thin film transistors by surface treatment of polysilsesquioxane gate dielectric layers", Journal of the Society of Materials Science Japan, Vol. 65, Issue 9, pp. 652-655 (2016).

14) M. Cypryk and Y. Apeloig, "Mechanism of the acid-catalyzed Si-O bond cleavage in siloxanes and siloxanols. A theoretical study”, Organometallics, Vol. 21, No. 11, pp. 2165-2175 (2002). 